11

\title{
Соинтеркалация дихалькогенидов титана переходными металлами
}

\section{и медью}

\author{
(C) А.А. Титов ${ }^{1}$, А.Н. Титов ${ }^{1,2, \uparrow, ~ С . Г . ~ Т и т о в а ~}{ }^{3}$, С.В. Пряничников ${ }^{3}$, Д.С. Чезганов ${ }^{2}$ \\ ${ }^{1}$ Институт физики металлов УрО РАН, \\ Екатеринбург, Россия \\ ${ }^{2}$ Уральский федеральный университет им. Б.Н. Ельцина, \\ Екатеринбург, Россия \\ ${ }^{3}$ Институт металлургии УрО РАН, \\ Екатеринбург, Россия \\ ฯ E-mail: antitov@mail.ru
}

(Поступила в Редакцию 2 февраля 2016 г.

В окончательной редакции 10 марта 2016 г.)

Изучены соинтеркалатные материалы, получаемые при внедрении меди в решетку $\mathrm{TiSe}_{2}$, предварительно интеркалированную переходными металлами $M=\mathrm{Mn}, \mathrm{Fe}, \mathrm{Co}$, Ni. Анализ состояния соинтеркалированных систем при $950^{\circ} \mathrm{C}$ показывает, что медь восстанавливает Mn и Fe, однако не способна восстановить Со и $\mathrm{Ni}$. Для объяснения результатов сравниваются величины энергии связи гибридных состояний $M 3 d / \mathrm{Ti} 3 d$.

Эксперимент выполнен с использованием оборудования Центров коллективного пользования „Урал-М“ в ИМЕТ УрО РАН и „Современные нанотехнологии“ в УрФУ.

Работа выполнена в рамках государственного задания ФАНО РФ (тема „Спин“, № 01201463330), комплексной программы УрО РАН (проект № 15-9-2-30), государственного задания Министерства образования и науки РФ (UID RFMEFI59414Х0011) и РФФИ (грант № 4-03-00274).

DOI: 10.21883/FTT.2017.01.43964.35

\section{1. Введение}

Интеркалация слоистых дихалькогенидов титана позволяет создавать материалы с новыми физическими свойствами и упорядочениями интеркаланта [1,2]. Например, интеркалация железом и хромом позволяет формировать сложные магнитные структуры - длиннопериодические несоразмерные магнитные подрешетки и метамагнитные материалы [3,4]. Интеркалация хромом обеспечивает полную спиновую поляризацию состояний на уровне Ферми [5]. Разнообразие свойств может быть усилено при одновременной интеркалации разных металлов [6,7]. Этот подход ограничен в области высоких концентраций примеси, когда один из интеркалантов вытесняется другим, чье присутствие в решетке-матрице наиболее выгодно термодинамически [8]. Информация о пределах устойчивости и механизме распада интеркалированных двумя разными металлами дихалькогенидов титана позволит вести направленный синтез новых магнитных материалов, создавать композитные материалы, состоящие из включений металлов или их халькогенидов в межслоевом пространстве решетки-матрицы. Для этого необходимо выяснить, как особенности химической связи интеркалантов с решеткой-матрицей влияют на границу существования однородного состояния интеркалированного двумя металлами соединения. В настоящей работе исследовано изотемпературное сечение диаграммы равновесия систем $\mathrm{Cu}-M_{0.25} \mathrm{TiSe}_{2}$, где $M=\mathrm{Mn}, \mathrm{Fe}, \mathrm{Co}, \mathrm{Ni}$. Известно, что при интеркалации переходные металлы занимают октаэдрически координированную селеном позицию $[4,8,9]$, формируя связи $M-\mathrm{Ti}-M$ в направлении нормали к слоям решетки-матрицы (рис. 1). Изменяя тип металла в ряду $\mathrm{Mn}-\mathrm{Fe}-\mathrm{Co}-\mathrm{Ni}$ и соответственно параметры химической связи интеркалированного переходного металла, планировали исследовать область равновесия соинтеркалированного состояния, когда второй внедренный металл - медь. Медь выбрана потому,

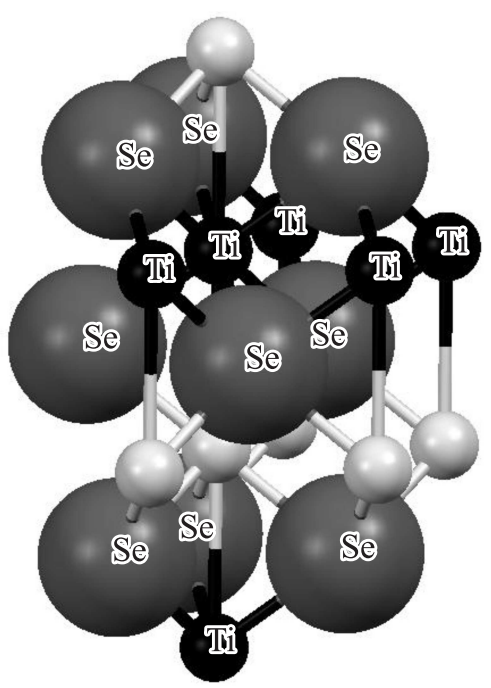

Рис. 1. Схематическое изображение элементарной ячейки $\mathrm{TiSe}_{2}$, неподписанные атомы соответствуют интеркалированному переходному металлу. 
что она не изменяет электронной структуры решетки матрицы [9] и, благодаря высокому коэффициенту диффузии, быстро распространяется по ней [10]. Связь железа, кобальта и никеля с решеткой диселенида титана преимущественно ковалентна [11]; энергия связи кобальта и никеля выше, чем у железа. Связь марганца с решеткой диселенида титана носит преимущественно ионный характер [12].

\section{2. Методики экспериментов}

Для синтеза соинтеркалатных соединений диселенида титана использовали титан, очищенный иодидной дистилляцией чистотой 99.99\%, медь ОСЧ 11-4 электролитическую чистотой $99.99 \%$, марганец, кобальт и электролитический никель чистотой 99.95\%, железо карбонильное, восстановленное в потоке водорода, чистотой 99.999\% и селен элементарный марки ОСЧ 19-5, чистотой 99.995\%. На первом этапе синтезировали $\mathrm{TiSe}_{2}$ методом ампульного синтеза в откачанных до $10^{-5}$ Torr. кварцевых ампулах при температуре $973 \mathrm{~K}$ в течение недели. По данным рентгенофазового анализа (дифрактометр XRD 7000 Maxima, $\mathrm{Cu} K_{\alpha}$-излучение, графитовый монохроматор, шаг съемки $0.02^{\circ}$, интервал углов рассеяния $2 \theta=12-90^{\circ}$ ) полученный диселенид титана не содержал примесных фаз, параметры элементарной ячейки совпадали с литературными данными [13] в пределах погрешности. На втором этапе в $\mathrm{TiSe}_{2}$ внедряли $M=\mathrm{Mn}, \mathrm{Fe}, \mathrm{Co}$ или Ni. Гранулы переходного металла и порошок $\mathrm{TiSe}_{2}$ прессовали в таблетки диаметром $10 \mathrm{~mm}$, высотой 5-6 mm, запаивали в вакуумированные кварцевые ампулы и отжигали неделю при температуре 1223 К. Для достижения однородности предпринимали промежуточный гомогенизирующий отжиг: образцы перетирали в агатовой ступке, вновь прессовали, запаивали и отжигали неделю при температуре $1223 \mathrm{~K}$. Рентгенофазовый анализ полученных образцов $M_{0.25} \mathrm{TiSe}_{2}$ не обнаружил посторонних фаз, значения параметров элементарной ячейки находились в хорошем согласии с литературными данными $[2,14,15]$. На третьем этапе аналогичным образом, с промежуточным перетиранием, в $M_{0.25} \mathrm{TiSe}_{2}$ внедряли медь при той же температуре 1223 К. Параметры элементарной ячейки как функция содержания меди без учета упорядочения интеркаланта приведены на рис. 2.

Методом газотранспортных реакций в вакуумированных ампулах с использованием иода в качестве газаносителя выращены монокристаллы соинтеркалатных соединений $(\mathrm{Cu}, \mathrm{Fe}) \mathrm{TiSe}_{2}$ и $(\mathrm{Cu}, \mathrm{Mn}) \mathrm{TiSe}_{2}$. Их состав проанализирован методом рентгеноспектрального микроанализа (EDS) с помощью электронного микроскопа Carl Zeiss AURIGA CrossBeam. На этом же микроскопе получены изображения монокристаллов соинтеркалатных соединений. Параметры элементарной ячейки по данным порошковой дифракции рассчитывали методом наименьших квадратов по 15-17 дифракционным линиям, критерием правильности расчета являлась вели-

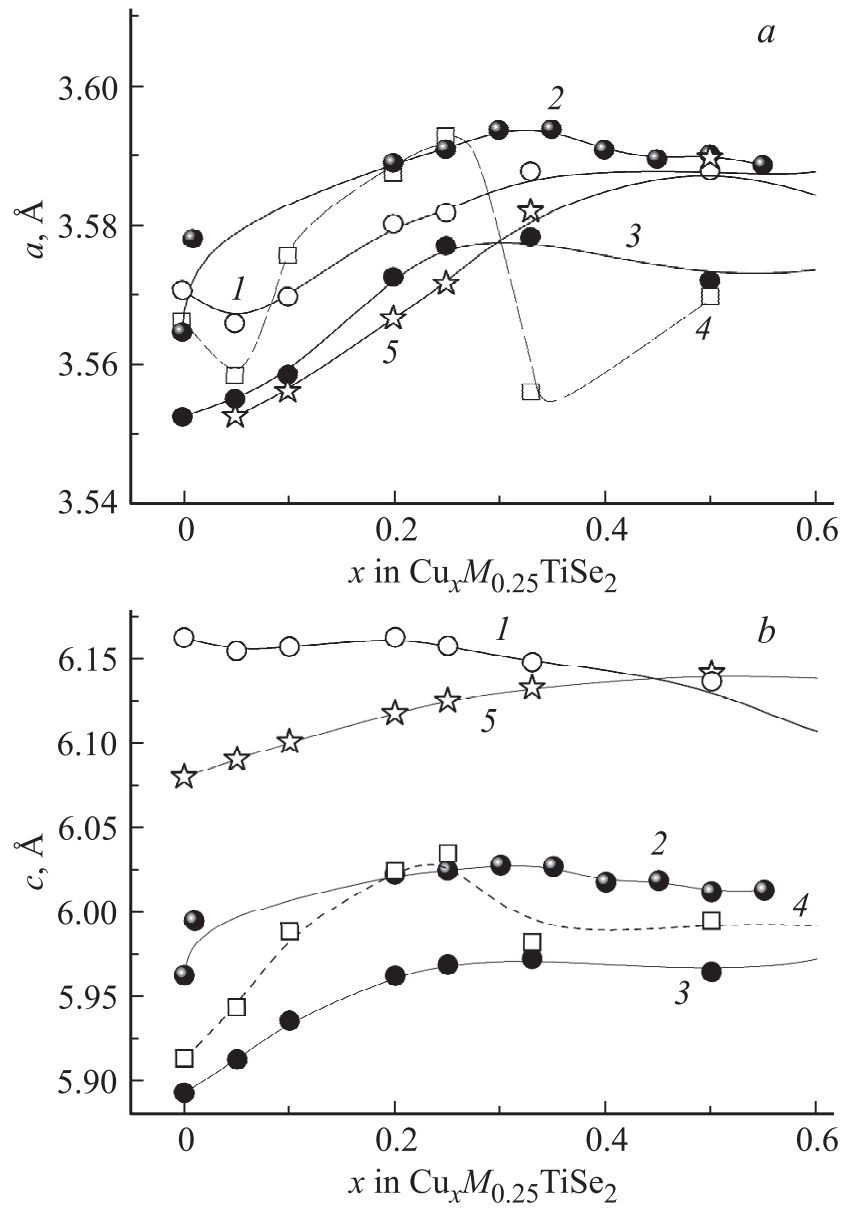

Рис. 2. Параметры элементарной ячейки $\mathrm{Cu}_{x} M_{0.25} \mathrm{TiSe}_{2}$, где $M$ - Mn (1), Fe (2), Co (3), Ni (4) и $\mathrm{Cu}_{x} \mathrm{Mn}_{0.1} \mathrm{TiSe}_{2}$ (5) в зависимости от содержания меди $x$. $(a)$ - параметр элементарной ячейки $a,(b)-$ параметр $c$. Здесь и далее: пунктирные линии проведены произвольно, остальные линии проведены с помощью $\beta$-сплайнов.

чина Figure-of-Merit, характеризующая совпадение наблюдаемой и рассчитанной дифракционной картины по формуле

$$
F_{n}=\left(\frac{1}{|\overline{\Delta 2 \Theta}|}\right)\left(\frac{n}{n_{\text {poss }}}\right),
$$

где $|\overline{\Delta 2 \Theta}|=2 \theta_{\text {calc }}-2 \theta_{\text {obs }}-$ среднее отклонение положения наблюдаемой дифракционной линии от расчетного значения, $n_{\text {poss }}$ - количество наблюдаемых дифракционных линий во всем исследуемом диапазоне углов $2 \theta$, $n$ - количество линий, используемых для расчета параметров элементарной ячейки. В случае однофазного образца при использовании в расчете всех наблюдаемых дифракционных линий, при $|\overline{\Delta 2 \Theta}| \sim 0.02$ величина $F_{15} \sim 50$. Для наших образцов $F_{15} \sim 25$, поскольку даже при небольшом содержании интеркаланта образуются примесные фазы в количестве до $5 \mathrm{wt} . \%$ из-за взаимодействия интеркаланта с паром селена с последующим кинетическим затруднением распада селенида переходного металла. Существенный и быстрый рост количества 


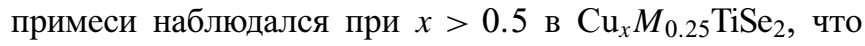
интерпретировано как предел растворимости соинтеркалатного соединения.

\section{3. Результаты и обсуждение}

Кристаллическая структура $\mathrm{TiSe}_{2}$ описывается пространственной группой $P \overline{3} m 1$. Как уже отмечалось, интеркалированные атомы переходного металла занимают октаэдрически координированную селеном позицию в межслоевом пространстве $[4,8,9,16]$, при этом они дважды координированы атомами титана (рис. 1). На рентгенограммах материалов $\mathrm{Co}_{0.25} \mathrm{TiSe}_{2}, \mathrm{Ni}_{0.25} \mathrm{TiSe}_{2}$ и $\mathrm{Fe}_{0.25} \mathrm{TiSe}_{2}$ наблюдались очень слабые дифракционные линии, соответствующие упорядочению интеркаланта и формированию сверхструктуры типа $a_{0} \sqrt{3} \times 2 a_{0} \times 2 c_{0}$, что согласуется с литературными данными [14]. Поскольку интенсивность сверхструктурных дифракционных линий не превышала $5 \%$, мы сочли возможным пренебречь эффектами упорядочения интеркаланта.

При концентрации меди $\sim 50$ mol.\% наблюдалось выделение второй фазы: селенида марганца, железа или селенида железа, селенидов кобальта и никеля, селенида меди. Изображение монокристаллов $(\mathrm{Cu}, \mathrm{Fe}) \mathrm{TiSe}_{2}$ и $(\mathrm{Cu}, \mathrm{Mn}) \mathrm{TiSe}_{2}$, полученное с помощью электронного сканирующего микроскопа, приведено на рис. 3 , 4. Видны выделения железа темного цвета плоской формы и выделения селенида меди в виде дендритов. Химический анализ дендрита (EDS) подтверждает, что медь выделяется в виде селенида меди (рис. $4, b$ ).

Анализируя рис. 2, можно видеть, что параметр ячейки $a(x)$ растет по крайней мере до $x<0.3$ для всех исследованных материалов $\mathrm{Cu}_{x} M_{0.25} \mathrm{TiSe}_{2}$, кроме области очень малых концентраций $0<x<0.05$ для интеркалатов на основе марганца и никеля (кривые 1 и 4 на рис. $2, a$ соответственно). Параметр ячейки $c(x)$ для составов $\mathrm{Cu}_{x} M_{0.25} \mathrm{TiSe}_{2}$ убывает в этом же диапа-

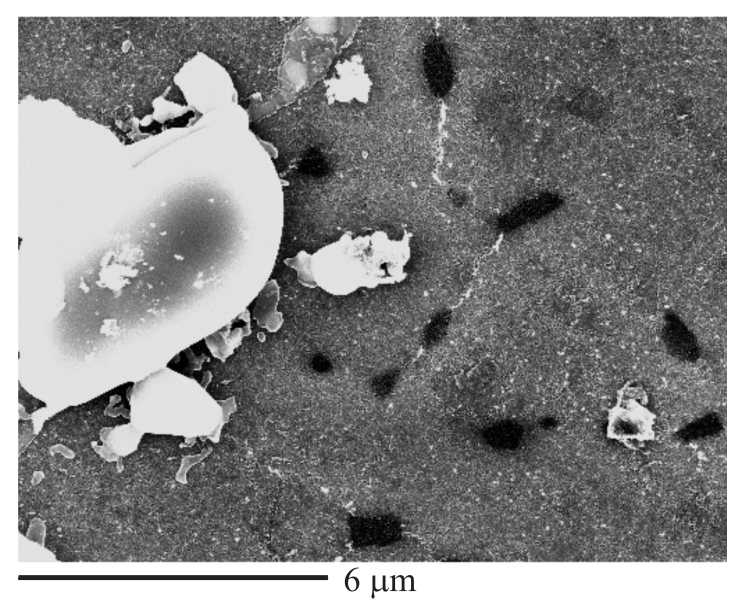

Рис. 3. Изображение монокристалла диселенида титана, интеркалированного одновременно медью и железом. Видны выделения железа в виде включений темного цвета.
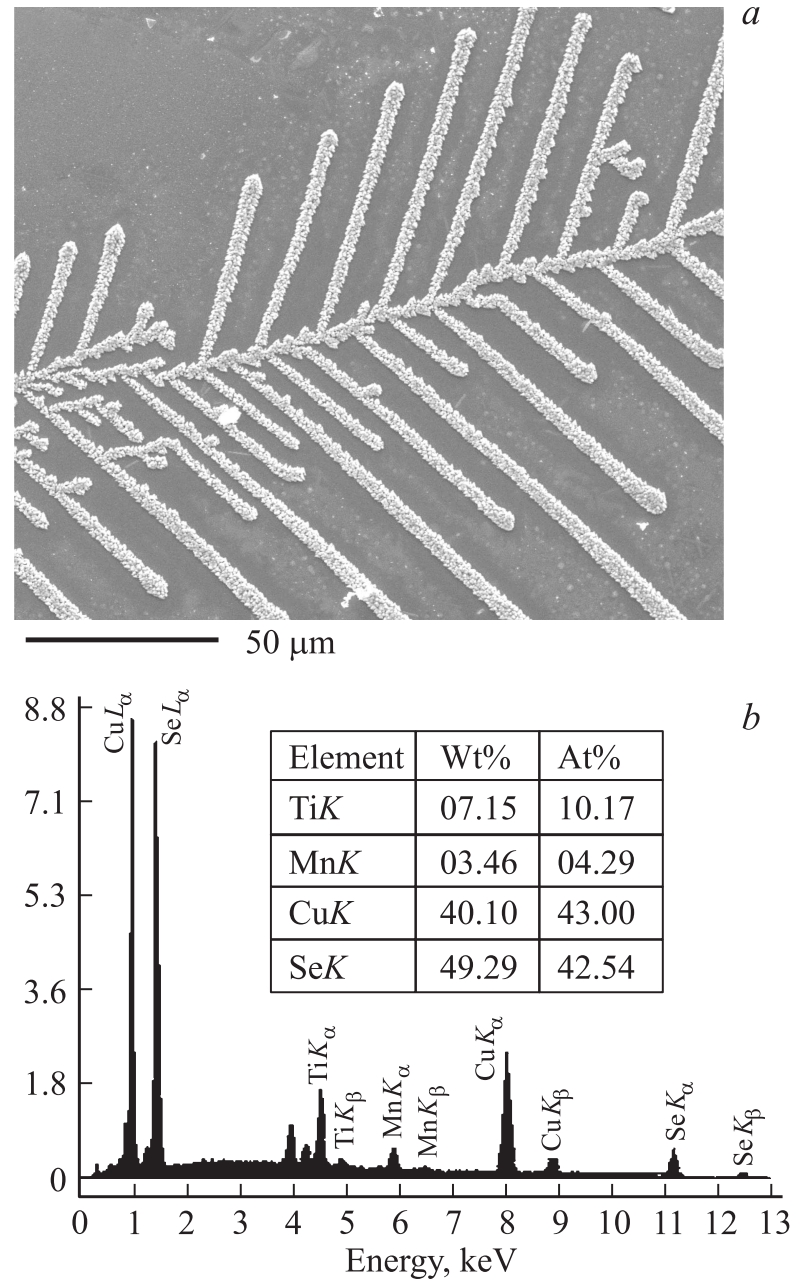

Рис. 4. Изображение монокристалла диселенида титана, интеркалированного одновременно медью и марганцем. $(a)-$ выделения селенида меди в виде дендрита, $(b)-$ результат анализа состава дендрита методом EDS.

зоне $x$, кроме случая $M=\operatorname{Mn}$ (кривая 1 на рис. $2, b)$. По-видимому, изменение хода зависимостей $a(x)$ и $c(x)$ при $x>0.3$ обусловлено взаимодействием в подрешетке интеркаланта. Как уже отмечалось, именно поведение межслоевого расстояния $c(x)$ отражает особенности химической связи интеркаланта с решеткой. Чтобы понять причину отличия поведения $c(x)$ для системы с $M=\mathrm{Mn}$ от остальных материалов дополнительно была синтезирована еще одна система $\mathrm{Cu}_{x} \mathrm{Mn}_{0.1} \mathrm{TiSe}_{2}$ с меньшим содержанием марганца, концентрационная зависимость параметров элементарной ячейки для нее приведена на рис. 2 (кривая 5). Видно, что для этой системы зависимость параметра ячейки $c(x)$ от содержания меди, также как это наблюдалось ранее $[16,17]$ в системе $\mathrm{Cu}_{x} \mathrm{TiSe}_{2}$, демонстрирует параболическую зависимость. Следовательно, повышение концентрации марганца с 10 до 25 mol.\% приводит к принципиальным изменениям во взаимодействии меди с решеткой-матрицей в системе $\mathrm{Cu}_{x} \mathrm{Mn}_{y} \mathrm{TiSe}_{2}$. В обоих случаях $(y=0.1$ и $y=0.25)$ 
Параметры параболической аппроксимации концентрационной зависимости $c$-параметра элементарной ячейки соинтеркалатных материалов

\begin{tabular}{l|c|c}
\hline \multicolumn{1}{c|}{ Состав } & $\alpha, \AA$ & $\gamma, \AA$ \\
\hline $\mathrm{Cu}_{x} \mathrm{TiSe}_{2}$ & 0.22 & 0.01 \\
$\mathrm{Cu}_{x} \mathrm{Mn}_{0.1} \mathrm{TiSe}_{2}$ & 0.12 & 0.01 \\
$\mathrm{Cu}_{x} \mathrm{Fe}_{0.25} \mathrm{TiSe}_{2}$ & 0.30 & -0.77 \\
$\mathrm{Cu}_{x} \mathrm{Co}_{0.25} \mathrm{TiSe}_{2}$ & 0.25 & -0.27 \\
$\mathrm{Cu}_{x} \mathrm{Ni}_{0.25} \mathrm{TiSe}_{2}$ & 0.41 & -0.60
\end{tabular}

медь вытесняла марганец из решетки диселенида титана; относительная интенсивность дифракционных линий селенида марганца возрастала с ростом содержания меди.

Параболическая зависимость функции $c(x)$ наблюдается для составов $\mathrm{Cu}_{x} M_{0.25} \mathrm{TiSe}_{2}$ с $M=\mathrm{Fe}, \mathrm{Co}, \mathrm{Ni}$ (по крайней мере, до $x<0.3$ ) и $\mathrm{Cu}_{x} \mathrm{Mn}_{0.1} \mathrm{TiSe}_{2}$; это позволило нам провести аппроксимацию $c(x)$ таким же образом, как это было сделано ранее для систем $\mathrm{Cu}_{x} \mathrm{TiSe}_{2}$ [17] и $(\mathrm{Cu}, \mathrm{Fe}) \mathrm{TiSe}_{2}$ [16]. Предполагалось, что медь случайным образом распределяется по доступным октаэдрическим позициям в межслоевом пространстве. Если пренебречь взаимодействием между интеркалированными атомами, то внедрение каждого атома меди приводит к изменению межплоскостного расстояния из-за смещения ближайшего атома титана на одинаковую величину $\alpha$. Тогда для системы $\mathrm{Cu}_{x} \mathrm{TiSe}_{2}$ концентрационная зависимость параметра ячейки вдоль $c$-оси (межслоевого расстояния) выражается следующим образом:

$$
c(x)=c_{0}+\alpha \cdot p_{a}+\gamma \cdot p_{s}(x),
$$

где $c_{0}$ - параметр ячейки исходного $\mathrm{TiSe}_{2}$ (в данном случае исходным составом будет $M_{0.25} \mathrm{TiSe}_{2}, M=\mathrm{Fe}, \mathrm{Co}$, $\mathrm{Ni}$ или $\left.\mathrm{Mn}_{0.1} \mathrm{TiSe}_{2}\right), p_{a}(x)$ - вероятность осуществления асимметричной конфигурации $\mathrm{V}-\mathrm{Ti}-M$ или $M-\mathrm{T}-\mathrm{V}$ в направлении $c$-оси, $p_{s}(x)$ - вероятность симметричной конфигурации $M-\mathrm{Ti}-M$ (полагаем, что конфигурация $\mathrm{V}-\mathrm{Ti}-\mathrm{V}$ не вызывает искажения решетки), V - вакансия. В случае соинтеркалации при расчете $p(x)$ учитывали то обстоятельство, что часть позиций уже занята атомом переходного металла (подробнее см. в работе [16]). Результаты аппроксимации приведены в таблице и на рис. 5. Погрешности определения величин $\alpha$ и $\gamma$ не превышают $0.02 \AA$. Полученные для $\mathrm{Cu}_{x} \mathrm{TiSe}_{2}$ результаты в пределах погрешности совпадают с данными работы [16], где было получено $\alpha=0.27 \AA$, $\gamma=-0.009 \AA$.

Сравнивая исследованные интеркалированные системы (см. таблицу), можно видеть, что в случае системы, предварительно интеркалированной марганцем (только для небольшого содержания марганца $y=0.1)$ атом меди приводит к более слабому смещению атомов титана по сравнению с исходным $\mathrm{TiSe}_{2}$ (для системы $\left.\mathrm{Cu}_{x} \mathrm{TiSe}_{2}\right)$ и $M_{0.25} \mathrm{TiSe}_{2}$, где $M$ - другой переходный металл; искажение решетки для системы с никелем
$\mathrm{Cu}_{x} \mathrm{Ni}_{0.25} \mathrm{TiSe}_{2}$ максимально. Во всех случаях $\alpha>0$, т.е. во всех случаях внедрение меди приводит к росту межплоскостного расстояния при увеличении вероятности несимметричных конфигураций $\mathrm{V}-\mathrm{Ti}-\mathrm{Cu}$ или $\mathrm{Cu}-\mathrm{Ti}-\mathrm{V}$. Величины $\gamma$ очень малы и положительны для систем только с медью и составов с медью и марганцем, что означает очень слабое увеличение межплоскостного расстояния при увеличении количества симметричных конфигураций $\mathrm{Cu}-\mathrm{Ti}-\mathrm{Cu}$. Для других переходных металлов $M=\mathrm{Fe}, \mathrm{Co}, \mathrm{Ni}$ величины $\gamma$ отрицательны и по абсолютной величине сравнимы или превышают $\alpha$; это означает, что увеличение количества дважды координированного медью титана приводит к сжатию межплоскостного расстояния этих соинеркалатных соединений. $\mathrm{B}$ то же время известно, что интеркалация $\mathrm{Fe}, \mathrm{Co}$ и $\mathrm{Ni}$ в $\mathrm{TiSe}_{2}$ также приводит к сжатию межплоскостного расстояния $[14,18-20]$, интеркалация $\mathrm{Mn}$ и $\mathrm{Cu}-$ к его увеличению [17-21]. Поэтому естественно, что в случае системы с марганцем $\mathrm{Cu}_{x} \mathrm{Mn}_{0.1} \mathrm{TiSe}_{2}$ величина $\alpha$ почти в два раза меньше, чем в случае чистого $\mathrm{TiSe}_{2}$ : медь конкурирует с марганцем при сонаправленном смещении титана. Противоположная тенденция наблюдается при соинтеркалации меди и никеля: здесь меди удается сместить атомы титана существенно сильнее, чем в чистом $\mathrm{TiSe}_{2}$. Как представляется, это происходит потому, что внедрение никеля вызвало сжатие межплоскостного расстояния, поэтому последующая интеркалация меди значительно сильнее сказывается на увеличении параметра элементарной ячейки.

Для исследования вытеснения железа медью предприняты отжиги образца $\mathrm{Cu}_{0.5} \mathrm{Fe}_{0.25} \mathrm{TiSe}_{2}$ от разных температур. Минимальная температура, при которой зафиксировано выделение железа, составляет 923 К. С ростом температуры количество вытесненного железа растет, что согласуется с данными о ретроградной растворимости железа в диселениде титана [22].

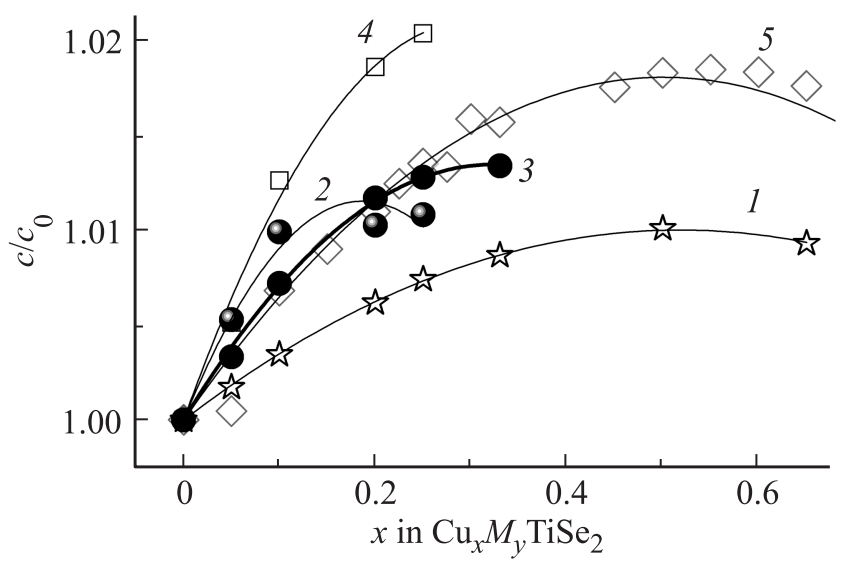

Рис. 5. Параболическая аппроксимация $c$-параметра элементарной ячейки, отнесенного к параметру ячейки для соответствующего материала с $x=0$ для систем $\mathrm{Cu}_{x} \mathrm{Mn}_{0.1} \mathrm{TiSe}_{2}(1)$ и $\mathrm{Cu}_{x} M_{0.25} \mathrm{TiSe}_{2}$, где $M-\mathrm{Fe}(2), \mathrm{Co}(3), \mathrm{Ni}(4)$ в зависимости от содержания меди. Данные для системы $\mathrm{Cu}_{x} \mathrm{TiSe}_{2}(5)$ взяты из работы [12] для сравнения. 
Для объяснения наблюдаемых результатов рассмотрим следующую модель. Граница равновесия $\mathrm{Cu}_{x} \mathrm{TiSe}_{2} M_{y} \mathrm{TiSe}_{2}$ определяется условием равенства свободных энергий фаз $\mathrm{Cu}_{x} \mathrm{TiSe}_{2}$ и $M_{y} \mathrm{TiSe}_{2}$

$$
\Delta G_{\mathrm{Cu}}=H_{\mathrm{Cu}}-T \cdot S_{\mathrm{Cu}}=\Delta G_{M}=H_{M}-T \cdot S_{M} .
$$

Индексы $\mathrm{Cu}$ и $M$ относятся к фазам $\mathrm{Cu}_{x} \mathrm{TiSe}_{2}$ и $M_{y} \mathrm{TiSe}_{2}$ соответственно. Тогда для температуры выделения металла $T_{\text {ext }}$ справедливо равенство

$$
T_{\mathrm{ext}}=\left(H_{\mathrm{Cu}}-H_{M}\right) /\left(S_{\mathrm{Cu}}-S_{M}\right) .
$$

Диффузионная подвижность меди в решетке $\mathrm{TiSe}_{2}$ близка по своей величине к подвижности ионов в суперионных соединениях [10]. Это указывает на малость энергии активации диффузии и, следовательно, более равномерное распределение ионов меди по позициям в решетке $\mathrm{TiSe}_{2}$ по сравнению с переходными металлами, не имеющими столь высокой диффузионной подвижности. Это, в свою очередь, означает, что конфигурационный вклад в энтропию соединений с медью должен быть выше, чем в случае соединений других переходных металлов. Возможно, именно это обстоятельство и приводит к большей устойчивости соединений с медью в пределе высоких температур. Близость коэффициентов диффузии других переходных металлов и одинаковый характер их распределения в решетке позволяет предположить, что конфигурационный вклад в энтропию этих материалов, связанный с подсистемой интеркаланта, будет если не одинаков, то близок. Это означает, что знаменатель в выражении (2) можно принять постоянным и обозначить $\Delta S$ для всех обсуждаемых материалов. Тогда различие в устойчивости относительно выделения переходного металла будет определяться только разностью энтальпий растворения меди и другого переходного металла. В работе [18] энергию удельной деформации решетки в расчете на атом интеркаланта при растворении переходных металлов удалось связать с величиной энергии связи формирующейся при интеркалации зоны гибридных Ti3d/M3d ( $M$ - переходный металл) состояний $E_{b}$, которая составляет $-0.1,-0.24$ и $-0.25 \mathrm{eV}$ относительно уровня Ферми для систем с $\mathrm{Fe}, \mathrm{Ni}$ и $\mathrm{Co}$ соответственно. Величина $E_{b}$ совпадает с энтальпией $H_{M}$ с точностью до ионного вклада, который будем считать одинаковым для всех переходных металлов ввиду близости их ионных радиусов. С другой стороны, энергия деформации решетки может быть выражена следующим образом [18] (оценка снизу, без учета эффективного заряда внедренного иона)

$$
\Delta E=S \cdot \alpha^{2} / \kappa_{c} \cdot c,
$$

где $S=a^{2} \sin 60^{\circ}$ - площадь базисной плоскости элементарной ячейки, $a$ и $c-$ параметры элементарной ячейки, $\alpha-$ изменение межплоскостного расстояния при внедрении одного атома, $\kappa_{c}=\frac{1}{c} \frac{d c}{d p}-$ сжимаемость в направлении $c$-оси. Мы использовали сжимаемость для $\mathrm{TiSe}_{2} \kappa_{c}=1.53 \cdot 10^{-11} \mathrm{~Pa}[18]$ без учета влияния интеркалации. Конечно, отнесение величины, полученной для исходного, неинтеркалированного материала к интеркалированному представляет собой некое допущение. Однако в концентрационном интервале $x=0-0.25$ $c$-параметр показывает линейную концентрационную зависимость для $M_{x} \mathrm{TiSe}_{2}, M=\mathrm{Fe}, \mathrm{Co}, \mathrm{Ni}$ [18-20], что возможно только при внесении каждым внедряемым атомом совершенно одинакового искажения в решетку. Если бы сжимаемость материала заметно изменялась в этой области составов, то эта зависимость не могла бы оставаться линейной. Приравнивая рассчитанную таким образом величину $\Delta E=5.37 \cdot 10^{-2} \mathrm{eV}$ к энтальпии $H_{\mathrm{Cu}}$ и используя экспериментально полученную величину $T_{\text {extr }}=923 \mathrm{~K}$ для $\mathrm{Fe}$, из выражения (2) можно получить $\Delta S=1.665 \cdot 10^{-4} \mathrm{eV} / \mathrm{K}$. Тогда сразу получаем температуры выделения никеля и кобальта $1764 \mathrm{~K}$ и $1824 \mathrm{~K}$ соответственно; эти значения существенно выше температуры исследования $1223 \mathrm{~K}$.

\section{4. Заключение}

Рассмотрена соинтеркалация диселенида титана медью и другими переходными металлами: марганцем, кобальтом, никелем и железом; все интеркалированные атомы занимают в решетке-матрице позиции в межслоевом пространстве таким образом, что оказываются двукратно координированы титаном в направлении нормали к слоям решетки-матрицы. Полученные результаты указывают на то, что устойчивость интеркалатных соединений определяется энергией химической связи интеркаланта с решеткой, которая, в свою очередь, зависит от энергии гибридизованных $M 3 d / \mathrm{Ti} 3 d$-состояний, $M-$ переходный металл. Можно ожидать, что при повышении содержания переходного металла (выше $x>0.3$ ) энтропия соединения будет понижаться вследствие упорядочения интеркаланта. Тогда, согласно формуле (2) должна снижаться и температура начала восстановления металлов при соинтеркалации меди. Свободная энергия системы $\mathrm{Cu}_{x} \mathrm{TiSe}_{2}$ как функция состава и температуры может быть определена электрохимическими методами, благодаря высокой диффузионной подвижности ионов меди. Использование предложенного в настоящей работе подхода позволяет вычислить термодинамические функции интеркалатов с переходными металлами по положению границы устойчивости однородного соинтеркалатного материала на плоскости состав-температура.

\section{Список литературы}

[1] Tjipke Hibma. J. Solid State Chem. 34, 97 (1980).

[2] G. Calvarin, J.R. Gavarri, M.A. Buhanic, P. Colombet, M. Danot. Rev. Phys. Appl. 22, 1131 (1987).

[3] N.V. Baranov, E.M. Sherokalova, N.V. Selezneva, A.V. Proshkin, A.F. Gubkin, L. Keller, A.S. Volegov, E.P. Proskurina. J. Phys.: Condens. Matter 25, 066004 (2013). 
[4] N.V. Baranov, A.N. Titov, V.I. Maksimov, N.V. Toporova, A. Daoud-Aladine, A. Podlesnyak. J. Phys.: Condens. Matter 17, 5255 (2005).

[5] M.V. Yablonskikh, A.S. Shkvarin, Yu.M. Yarmoshenko, A.I. Merentsov, M.V. Kuznetsov, A.N. Titov. J. Phys.: Conf. Ser. 425, 102004 (2013).

[6] Г.А. Такзей, М.В. Гавриленко, П. Ескуинази, Л.М. Куликов, И.И. Сыч. ФТТ 39, 1801 (1997).

[7] H. Negishi, A. Shoube, M. Koyano, Y. Muneta, M. Inour. J. Magn. Magn Mater. 60, 259 (1986).

[8] А.А. Титов, А.Н. Титов, О.В. Бушкова, В.А. Цурин. ФТТ 52, 1472 (2010).

[9] А.С. Шкварин, Ю.М. Ярмошенко, Н.А. Скориков, А.А. Титов, А.Н. Титов. ЖЭТФ 141, 366 (2012).

[10] А.А. Титов, А.И. Меренцов, А.Е. Карькин, А.Н. Титов, В.В. Федоренко. ФТТ 51, 217 (2009).

[11] А.Н. Титов, Т.В. Великанова. ФТТ 48, 1394 (2006).

[12] M.V. Yablonskikh, A.S. Shkvarin, Yu.M. Yarmoshenko, N.A. Skorikov, A.N. Titov. J. Phys.: Condens. Matter 24, 045504 (2012).

[13] J.A. Wilson, A.D. Yoffe. Adv. Phys. 18, 193 (1969).

[14] Y. Arnaud, M. Chevreton, A. Ahouanjinou, M. Danot, J. Rouxel. J. Solid State Chem. 17, 9 (1976).

[15] В.Г. Плещев, А.Н. Титов, Н.В. Баранов. ФТТ 44, 62 (2002).

[16] В.Ф. Балакирев, А.А. Титов. ФТТ 55, 542 (2013).

[17] А.А. Титов, В.Ф. Балакирев, А.С. Волегов, А.Н. Титов. ФTT 54, 1103 (2012).

[18] А.Н. Титов, А.В. Долгошеин, И.К. Бдикин, С.Г. Титова. ФTT 42, 1567 (2000).

[19] Y. Tazuke, T. Takeyama. J. Phys. Soc. Jpn 66, 827 (1977).

[20] В.Г. Плещев, Н.В. Топорова, А.Н. Титов, Н.В. Баранов. ФТT 46, 1153 (2004).

[21] V.I. Maksimov, N.V. Baranov, V.G. Pleschov, K. Inoue. J. Alloys Comp. 384, 33 (2004).

[22] Е.Г. Шкварина, В.А. Цурин, А.Н. Титов, С.Г. Титова, О.М. Федорова. ФТТ 54, 585 (2012). 